\title{
A Study to Assess Effectiveness of Teaching Methods on Retention of Knowledge among Nursing Students in Colleges of Pune City
}

\author{
Vaishali Agre $^{1}$, Dr. Kochu Thresiamma Thomas ${ }^{2}$ \\ ${ }^{1}$ Ph.D Nursing, National University of Medical Sciences, Jaipur, India \\ ${ }^{2}$ Nursing Research Expert, NIMS University,Jaipur
}

\begin{abstract}
Teaching methods has long since are used as an effective way to present information. Numerous teaching methods are used by teachers from traditional times to this Modern era. Therefore, exploring the efficacy of a variety of teaching methods for leadership educators is important due to the potential to determine best practices for classroom delivery. Purpose: To study the effectiveness of teaching Methods on retention of knowledge among nursing students. Objectives: To assess the effect of teaching methods on retention of knowledge among nursing students. Material and methods: This was a quantitative pre-experimental three group pre-test and post-test research design. The sample size was 300, divided into 100 for each method adopted for students of second Year B.Sc Nursing students for the subject of Medical Surgical Nursing. Probability cluster sampling technique was used for the selection of sample. Each group was having 100 samples and received Lecture Method in form of planned Lesson plan, Computer Aided Learning in the form of Power Point Presentation and Problem Based Learning in the form of situation formulated on Topic of Hypertension.Study was conducted in Bharati Vidyapeeth, Tilak mahavidyalaya,Sadhu vaswani,,D.Y.Patil,,Sinhgad and Themi grant Colleges of Nursing. Data collection was done by using demographic data of the samples, questionnaire was used to assess knowledge retention and Likert scale was used to assess students preferences, similarly open ended questionnaire was used to assess students opinion of teaching method that they consider valuable and least valuable and reasons for the same. Results: Computer Aided Learning has remarkably good knowledge retention and Lecture method has good effect on knowledge retention but Problem based learning has poor effect on knowledge retention but students valued and preferred Lecture method as the best method and consider Problem Based learning as least preferred and valuable method according to their opinion. Lecture method being most traditional method yet been most preferred method as compared to Computer aided Learning method and Problem based Learning method by the students. Conclusion: Computer aided learning is remarkably good effect on knowledge retention but students prefer Lecture method as best and consider it valuable.
\end{abstract}

Keywords: Teaching Methods, Lecture Method, Computer Aided Learning, Problem Based Learning, knowledge retention

\section{Introduction}

With the revolution in technology, education over the years has changed tremendously from paper, pen to computer. The traditional teaching methods are replaced by new advanced teaching methods, even laptops and computers are now passed with the entry of ipads. Blackboards are replaced by digital boards. Students are now technologically advanced which provide them answer for everything at instant speed. Interactive teaching and classroom imparts lot of practical knowledge $^{1}$

\section{Review of literature}

Academic excellence can create revolution in field of Nursing and its effect on quality patient care. One of the aims of health services in 21 st century is improvement in quality of life. ${ }^{2}$

Researches on teaching methods highlights that different categories of teaching methods exist and nearly 150 methods are incorporated in field of education from traditional times to modern times. ${ }^{3}$

Extensive search revealed that in the field of education in all the sciences researches are very sparse and similarly in
Nursing Education (Pulen, 2011) Thus this study was carried out to assess Effectiveness of Teaching Methods on Retention of Knowledge among Nursing students in Colleges of Pune city. ${ }^{4}$

\section{Research Methodology}

This study uses the quantitative research approach. A preexperimental study with three group pre-test post-test research design was considered best sited to the study. This design was used since the study evaluated the effect of teaching methods (independent variable) on knowledge retention of the students (dependent variables).

The investigator adapted Probability cluster sampling for Data Collection.

3.1. Setting: Bharati Vidyapeeth,Tilak mahavidyalaya, Themi Grant Institute of Nursing Education, Sadhu vaswani, ,D.Y.Patil, and Sinhgad Colleges of Nursing

3.2. Population: Second Year B.Sc Nursing students.

3.3. Sample Size: 300

3.4. Inclusive Criteria

- Second year B.Sc. Nursing students admitted to Selected Colleges of Pune city in the year 2013-14. 


\section{International Journal of Science and Research (IJSR) \\ ISSN (Online): 2319-7064}

Index Copernicus Value (2013): 6.14 $\mid$ Impact Factor (2015): 6.391

- Students those who had successfully completed First Year. B.Sc Nursing examination.

- Students those who were willing to participate in the study.

\subsection{Exclusive Criteria}

- Students who were allowed to attend classes of Second.Year.B.Sc Nursing but had not passed their FirstYear B.Sc Nursing Examination.

- Students who were awaited with the results of reevaluation of FirstYear.B.Sc Nursing Examination

\section{Description of the Tool}

\section{Section I: Demographic profile}

Section one was prepared to collect general information about the Second Year B.Sc Nursing students about variables such as:

- Age.

- Gender.

- Percentage of Marks HSC

- Percentage of Marks F.Y.B.Sc Nursing

\section{Section II: Tool to assess knowledge Retention.}

Knowledge questionnaire was formulated based on specific topic which was selected for Lecture Method,Computer Aided Learning and Problem Based Learning Method from Subject of Medical Surgical Nursing in specific Topic of Hypertension.

Questionnaire was formulated following aspects:

Meaning and Definition, Incidence, Risk Factors and Etiology,Pathophysiology,Investigations,Prevention,Complic ations, Medical Management and Nursing Management on Topic of Hypertension.

Knowledge tool consisted of thirty items, the scoring done was as follows: Correct answer-1, Wrong answer-0.Total score-30

Grading was done as below

\begin{tabular}{|c|c|}
\hline $0-8$ & Poor \\
\hline $9-16$ & Average \\
\hline $17-24$ & Good \\
\hline $25-30$ & Excellent \\
\hline
\end{tabular}

Section III: Tool to assess student's preferences for teaching Methods

Likert scale was used to assess students preferences, Scoring for Likert scale was done as follows, Total scoring was 28

\begin{tabular}{|l|l|}
\hline $0-7$ & Poor teaching Method \\
\hline $8-14$ & Average Teaching Method \\
\hline $15-28$ & Excellent teaching Method. \\
\hline
\end{tabular}

Section IV: Tool to assess students Opinion about teaching methods

a. Method to be Valuable and least valuable

b. What are the reasons for considering particular method so?

\section{Results and Analysis}

This part deals with the overall analysis of samples related to knowledge retention of students in selected colleges of pune city in terms of frequencies, percentage, average, and $t$ values.

Table 1: Demographic description of variables by frequency

\begin{tabular}{|c|c|c|}
\hline $\begin{array}{l}\text { Demographic } \\
\text { Parameters }\end{array}$ & $\frac{(\%)}{\text { Frequency }}$ & $\%$ \\
\hline Age & & \\
\hline 19 & 9 & $3 \%$ \\
\hline 20 & 267 & $89 \%$ \\
\hline 21 & 24 & $8 \%$ \\
\hline \multicolumn{3}{|c|}{ Gender } \\
\hline Female & 186 & $62 \%$ \\
\hline Male & 114 & $38 \%$ \\
\hline \multicolumn{3}{|c|}{$\%$ of marks in HSC } \\
\hline Distinction & 78 & $26 \%$ \\
\hline First Class & 120 & $40 \%$ \\
\hline Second Class & 69 & $23 \%$ \\
\hline Third Class & 33 & $11 \%$ \\
\hline \multicolumn{3}{|c|}{ \% of marks in F.Y.B.Sc Nursing. } \\
\hline Distinction & 84 & $28 \%$ \\
\hline First Class & 105 & $35 \%$ \\
\hline Second Class & 45 & $15 \%$ \\
\hline Third Class & 21 & $7 \%$ \\
\hline Failure & 18 & $6 \%$ \\
\hline A.T.K.T & 27 & $9 \%$ \\
\hline
\end{tabular}

The sample distribution in table 1 shows that $89 \%$ sample are of 20 years of age, $62 \%$ are female by gender, $40 \%$ scored First class in HSC,35\% scored First class in First Year B.Sc Nursing.

Table 2: Analysis of demographic data of samples according to teaching methods

\begin{tabular}{|c|c|c|c|}
\hline Demographic & $\begin{array}{l}\text { Lecture } \\
\text { method }\end{array}$ & $\begin{array}{l}\text { Computer Aided } \\
\text { Learning method }\end{array}$ & $\begin{array}{c}\text { Problem based } \\
\text { learning method }\end{array}$ \\
\hline \multicolumn{4}{|c|}{ Age } \\
\hline 19 & 3 & 3 & 3 \\
\hline 20 & 92 & 79 & 96 \\
\hline 21 & 11 & 8 & 5 \\
\hline \multicolumn{4}{|c|}{ Gender } \\
\hline Female & 40 & 95 & 51 \\
\hline Male & 38 & 26 & 50 \\
\hline \multicolumn{4}{|c|}{$\%$ of marks in HSC } \\
\hline Distinction & 15 & 45 & 18 \\
\hline First Class & 38 & 31 & 51 \\
\hline Second Class & 30 & 21 & 18 \\
\hline Third Class & 7 & 15 & 11 \\
\hline \multicolumn{4}{|c|}{$\%$ of marks in F.Y.B.Sc Nsg. } \\
\hline Distinction & 18 & 38 & 28 \\
\hline First Class & 17 & 29 & 59 \\
\hline Second Class & 21 & 15 & 9 \\
\hline \begin{tabular}{|l|} 
Third Class \\
\end{tabular} & 7 & 5 & 9 \\
\hline Failure & 5 & 6 & 7 \\
\hline A.T.K.T & 11 & 7 & 9 \\
\hline
\end{tabular}

Table 2 shows sample distribution according to the teaching method adopted 


\section{International Journal of Science and Research (IJSR) \\ ISSN (Online): 2319-7064 \\ Index Copernicus Value (2013): 6.14 | Impact Factor (2015): 6.391}

Lecture Method: $92 \%$ are of 20 years of age, $40 \%$ are females, $38 \%$ has scored first class in HSC and $21 \%$ has scored second class in F.Y.B.Sc Nursing.

Computer Aided Learning method:79\% are of 20 years of age. $95 \%$ are females, $45 \%$ scored distinction in HSC and $38 \%$ scored distinction in F.Y.B.Sc Nursing.

Problem Based Learning: $96 \%$ are of 20 years of age,51\% has scored first class in HSC and 59\% has scored first class in F.Y.B.Sc Nursing.

\section{Section II A:}

Table 3: Mean score of overall knowledge retention of students in Lecture method

\begin{tabular}{|c|c|c|c|c|l|}
\hline Skills & Mean & $S D$ & $T$ & $d f$ & $p$-value \\
\hline Pre-test & 9.6 & 3.3 & \multirow{2}{*}{15.5} & \multirow{2}{*}{99} & 0.000 \\
\hline Post-test & 14.3 & 3.5 & & & \\
\hline
\end{tabular}

The above table 3 indicates that there was a significant increase in the knowledge score from the pre-test to the posttest with a standard deviation of (3.3) and (3.5) respectively. The difference is significant at $(99 \%)$ confidence interval. $t$ value for this test was (15.5)and p-value for this comparison was 0.000 , which is small (less than 0.05) thus lecture method was found to have significant effect on knowledge retention of students.

\section{Section II B}

Table 4: Mean of overall knowledge retention of students in Computer Aided Learning method.

\begin{tabular}{|c|c|c|c|c|c|}
\hline Skills & Mean & $S D$ & $T$ & $d f$ & $p$-value \\
\hline Pre-test & 10 & 2 & \multirow{2}{*}{15.5} & 99 & 0.000 \\
\hline Post-test & 33.2 & 11.3 & & & \\
\hline
\end{tabular}

The above table 4 indicates that there was a significant increase in the knowledge score of pre-test to the post-test knowledge score with a standard deviation of (10.0) and (33.2) respectively. The difference is significant at $(99 \%)$ confidence interval. $\mathrm{t}$-value for this test was (15.5)and $\mathrm{p}$ value for this comparison was 0.000 , which is small (less than 0.05) thus Computer Aided Learning method was found to have highly significant effect on knowledge retention..

\section{Section II C}

Table 5: Mean of overall knowledge retention of students in Problem based learning method

\begin{tabular}{|l|l|l|c|c|c|}
\hline \multicolumn{1}{|c|}{ Skills } & Mean & \multicolumn{1}{|c|}{$S D$} & $T$ & $d f$ & $p$-value \\
\hline Pre-test & 6 & 2.1 & \multirow{2}{*}{15.5} & 99 & 0.000 \\
\hline Post-test & 12.5 & 1.8 & & & \\
\hline
\end{tabular}

The above table 5 indicates that there was a significant increase in the knowledge score from pre-test to the post-test with a standard deviation of (6.0) and (12.5) respectively. The difference is significant at $(99 \%)$ confidence interval. tvalue for this test was (15.5)and p-value for this comparison was 0.000 , which is small (less than 0.05) thus administration of problem based learning method was found to have poor effect on knowledge retention of students. Thus hypothesis $\mathrm{H} 3$ is rejected.

Comparing Lecture method and computer aided learning, the problem based learning has poor impact on knowledge retention.

\section{Section III A}

This section presents the Analysis of data related to the association of selected demographic variables with knowledge retention in lecture method.

Table 6: Association of Lecture Method with demographic variables

\begin{tabular}{|c|c|c|c|c|c|}
\hline Demographic & \multicolumn{5}{|c|}{ Pre-test knowledge scores } \\
\hline & Poor & Average & Good & Excellent & P-value \\
\hline \multicolumn{6}{|c|}{ 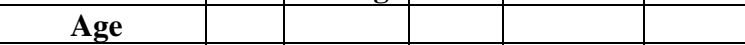 } \\
\hline 19 & 2 & 3 & 3 & 1 & \multirow{3}{*}{0.911} \\
\hline 20 & 106 & 43 & 75 & 43 & \\
\hline 21 & 4 & 8 & 7 & 5 & \\
\hline \multicolumn{6}{|l|}{ Gender } \\
\hline Female & 60 & 29 & 64 & 33 & \multirow{2}{*}{1.11} \\
\hline Male & 23 & 21 & 32 & 38 & \\
\hline \multicolumn{6}{|c|}{$\%$ marks in HSC } \\
\hline Distinction & 22 & 28 & 10 & 18 & \multirow{4}{*}{0.027} \\
\hline First Class & 28 & 11 & 47 & 34 & \\
\hline Second Class & 9 & 17 & 24 & 21 & \\
\hline Third Class & 7 & 9 & 11 & 6 & \\
\hline \multicolumn{6}{|c|}{ \% marks in F.Y.B.Sc Nsg. } \\
\hline Distinction & 12 & 35 & 16 & 21 & \multirow{6}{*}{0.012} \\
\hline First Class & 48 & 25 & 17 & 15 & \\
\hline Second Class & 7 & 11 & 20 & 7 & \\
\hline Third Class & 5 & 8 & 3 & 5 & \\
\hline Failure & 7 & 4 & 4 & 3 & \\
\hline A.T.K.T & 5 & 9 & 11 & 2 & \\
\hline
\end{tabular}

Since P-value corresponding to age and gender of the students was found to have no significant association while as percentage of marks in HSC and percentage of marks of F.Y.B.Sc Nursing the P-value is smaller than 0.05, thus has significant association with knowledge retention. Thus Section III B:

This section presents the Analysis of data related to the association of selected demographic variables with knowledge retention and teaching methods in computer aided learning.

Table 7: Association of Computer aided Learning Method with demographic variables

\begin{tabular}{|c|c|c|c|c|c|}
\hline $\begin{array}{c}\text { Demographic } \\
\text { Parameters }\end{array}$ & \multicolumn{5}{|c|}{ Pre-test knowledge scores } \\
\hline & Poor & Average & Good & Excellent & P-value \\
\hline Age & & & & & \\
\hline 19 & 2 & 3 & 3 & 1 & \multirow{2}{*}{0.751} \\
\hline 20 & 69 & 75 & 75 & 48 & \\
\hline 21 & 8 & 3 & 5 & 8 & \\
\hline \multicolumn{7}{|c|}{ Gender } \\
\cline { 1 - 5 } Female & 40 & 49 & 33 & 64 & \multirow{2}{*}{0.921} \\
\hline Male & 21 & 38 & 23 & 32 & \\
\hline \multicolumn{7}{|c|}{ \%of marks in HSC } \\
\cline { 1 - 4 } Distinction & 20 & 26 & 11 & 21 & \multirow{2}{*}{0.011} \\
\hline First Class & 47 & 11 & 28 & 34 & \\
\hline
\end{tabular}




\section{International Journal of Science and Research (IJSR) \\ ISSN (Online): 2319-7064}

Index Copernicus Value (2013): 6.14 | Impact Factor (2015): 6.391

\begin{tabular}{|c|c|c|c|c|c|}
\hline Second Class & 8 & 24 & 20 & 17 & \\
\hline Third Class & 11 & 6 & 7 & 9 & \\
\hline \multicolumn{7}{|c|}{ \% of marks in F.Y.B.Sc Nsg. } \\
\hline Distinction & 21 & 16 & 35 & 12 & \\
\hline First Class & 17 & 15 & 48 & 25 & \multirow{2}{*}{0.031} \\
\hline Second Class & 17 & 7 & 10 & 11 & \\
\hline Third Class & 3 & 5 & 5 & 8 & \\
\hline Failure & 4 & 3 & 7 & 4 & \\
\hline A.T.K.T & 11 & 2 & 5 & 9 & \\
\hline
\end{tabular}

Since P-value corresponding to age and gender of the students was found to have no significant association while as percentage of marks in HSC and percentage of marks of F.Y.B.Sc Nursing. P-value is smaller than 0.05 hence has significant association with knowledge retention.

\section{Section III C:}

This section presents the Analysis of data related to the association of selected demographic variables with knowledge retention in problem based learning. In order to find the association the data is analyzed using Fisher's exact test.

Table 8: Association of Problem based Learning Method with demographic variables

\begin{tabular}{|c|c|c|c|c|c|}
\hline \multirow{2}{*}{\begin{tabular}{|c|} 
Demographic \\
Parameters \\
\end{tabular}} & \multicolumn{5}{|c|}{ Pre-test knowledge scores } \\
\hline & Poor & Average & Good & Excellent & P-value \\
\hline \multicolumn{6}{|c|}{$\begin{array}{llll} & \\
\end{array}$} \\
\hline 19 & 81 & 58 & 50 & 78 & \multirow{3}{*}{0.821} \\
\hline 20 & 8 & 7 & 3 & 6 & \\
\hline 21 & 2 & 1 & 2 & 4 & \\
\hline \multicolumn{6}{|l|}{ Gender } \\
\hline Female & 22 & 66 & 26 & 72 & \multirow{2}{*}{1.21} \\
\hline Male & 20 & 52 & 19 & 23 & \\
\hline \multicolumn{6}{|c|}{ \% marks in HSC } \\
\hline Distinction & 11 & 31 & 13 & 23 & \multirow{4}{*}{0.013} \\
\hline First Class & 40 & 18 & 29 & 33 & \\
\hline \begin{tabular}{|l|} 
Second Class \\
\end{tabular} & 24 & 17 & 8 & 20 & \\
\hline Third Class & 7 & 7 & 10 & 9 & \\
\hline \multicolumn{6}{|c|}{ \% marks in F.Y.B.Sc Nursing. } \\
\hline Distinction & 35 & 12 & 16 & 21 & \multirow{6}{*}{0.028} \\
\hline First Class & 48 & 17 & 25 & 15 & \\
\hline Second Class & 7 & 11 & 10 & 17 & \\
\hline Third Class & 8 & 5 & 5 & 3 & \\
\hline Failure & 4 & 7 & 3 & 4 & \\
\hline A.T.K.T & 5 & 9 & 11 & 2 & \\
\hline
\end{tabular}

Since P-value corresponding to age and gender of the students was found to have no significant association while as percentage of marks in HSC P-value is smaller than 0.05, the HSC and percentage of marks of F.Y.B.Sc Nursing has significant association with knowledge retention.

\section{Section IV A:}

This section presents the students preference regarding the teaching methods to be most effective method of teaching.
Table 9: Mean score of student's preferences of teaching methods.

\begin{tabular}{|c|c|c|c|c|c|c|}
\hline Teaching method & $\begin{array}{c}\text { Mean } \\
\text { score }\end{array}$ & SD & $\mathrm{t}$ & $\mathrm{d}$ & $\mathrm{r}$ & $\mathrm{r} 2$ \\
\hline Lecture method & 3.04 & 1.285 & 2.57 & 0.24 & 0.12 & 0.014 \\
\hline Computer Aided learning & 1.93 & 1.02 & 1.90 & 0.18 & 0.09 & 0.008 \\
\hline Problem based method & 1.2 & 1.33 & 0.69 & 0.06 & 0.03 & 0.001 \\
\hline
\end{tabular}

When Lecture method was compared with computer aided learning and Problem based Learning methods, it was the only method to show statistical significance in the average mean difference in every comparison.

Computer aided learning and problem based learning is not as significant as compared to lecture method.

Students reported that they believed lecture method is the most preferred method of teaching.

The difference in average scores of effectiveness for lecture method when compared with other method of teaching was statistically significant $(\mathrm{t}=2.57,1.90,0.69)$.

\section{Section IV B:}

Table 10: Mean score of student's opinion of teaching methods.

\begin{tabular}{|c|c|c|c|c|c|c|}
\hline Teaching method & $\begin{array}{c}\text { Mean } \\
\text { score }\end{array}$ & SD & $\mathrm{t}$ & $\mathrm{d}$ & $\mathrm{r}$ & $\mathrm{r} 2$ \\
\hline Lecture method & 4.6 & 2.3 & 5.09 & 3.22 & 0.85 & 0.72 \\
\hline Computer Aided learning & 2.6 & 1.42 & 0.88 & 0.56 & 0.27 & 0.08 \\
\hline Problem based method & 0.9 & 1.3 & 0.26 & 0.16 & 0.1 & 0.01 \\
\hline
\end{tabular}

Student's opinion regarding Teaching method using lecture method, Computer Aided Learning and Problem based Learning highlights the mean score of 4.6, 2.6, 0.9 in which lecture method highlights significant mean score of 4.6 shows that in student opinion, lecture method is useful and valuable for them as compared to other two methods.

Section IV C: Reasons for why students consider specific method to be Valuable and least valuable.

Lecture method was considered valuable by $62 \%$ of students for the following reasons,

- Teachers making the lesson easier

- Teachers are well prepared

- References used by teacher is based on their knowledge and are best

- Blackboard method made it easier

- There is no diversion in Lecture method

- Notes given by teachers are more valuable and easily understood as well as it becomes easy during examination

- We mostly depend on the notes of teacher which we get in detail from the teachers.

- Utilization of teacher's notes is helpful during examination

- Most of the time lesson plan is well prepared

- Good control over class room makes environment feasible for good understanding that can be only done by teachers.

Reasons highlighted by students, Why Lecture Method of teaching is not considered as valuable 


\section{International Journal of Science and Research (IJSR) \\ ISSN (Online): 2319-7064}

Index Copernicus Value (2013): 6.14 | Impact Factor (2015): 6.391

- Same old notes are referred for years together by the teachers

- Sometimes it becomes monotonous and hence difficult to understand.

Computer Aided learning method was considered valuable by $28 \%$ of students for the following reasons,

- It can highlight about new concept of the particular content by referring different websites.

- New trends can be highlighted in the image form as it becomes easy

- Nursing should also follow same trend and technology as other profession hence nursing teachers should also us computers in their practice.

Why Computer Aided Learning is not considered as valuable

- Teachers download the PowerPoint presentation and are ready to deliver the lecture.

- Less efforts are taken by teachers so it becomes difficult for concept to be understood

- Teacher does not refer the books for the content of the subject.

Problem Based Learning method was considered valuable by $20 \%$ of students for the following reasons

Problem Based learning to be more valuable for the following reasons

- Students are actively involved hence it becomes easy to understand.

- Leadership qualities are developed.

- Decision making ability is improved.

- Confidence level enhances.

- More references are understood by students.

Why Problem Based learning is not considered as valuable

- It wastes lot of time

- It is difficult for Nursing students to utilize resources make topic understand and come ready for discussion due to heavy clinical assignments, clinical hours and lack of time

- It can be useful for higher classes and for Masters programe as compared to UG programmes.

It concludes that Computer Aided Learning has remarkably good knowledge retention, and Lecture method has good effect on knowledge retention but Problem based learning has poor effect on knowledge retention but students value and prefer Lecture method as the best method and consider Problem Based learning as least preferred and valuable method. Lecture method being most traditional method yet been most preferred method as compared to Computer aided method and Problem based method by the students.

Though statistically it has been proved that Computer aided learning is remarkably good effect on knowledge retention but students prefer Lecture method as best and consider it valuable, Similarly students has highlighted reasons why they consider specific Method to be valuable.

\section{Discussion}

The study concluded that Computer Aided Learning has remarkably good knowledge retention and Lecture method has good effect on knowledge retention but Problem based learning has poor effect on knowledge retention. Students value and prefer Lecture method as the best method and consider Problem Based learning as least preferred and valuable method. Lecture method being most traditional method yet been most preferred method as compared to Computer aided method and Problem based method by the students.

Though statistically it has been proved that Computer aided learning is remarkably good effect on knowledge retention but students prefer Lecture method as best and consider it valuable.

The result marked that there was significant knowledge retention in Nursing students using Problem based learning method[Cooper,2011] $]^{5}$ similarly study conducted on Lecture method in terms of knowledge retention highlights that significant increase in knowledge score using Lecture method (Les PS, Dupin , 2012) ${ }^{6}$

The results of this study highlights significant effect of Computer Aided Learning in terms of knowledge Retention and less effective is Problem Based Learning but many studies has proved significant effect of Lecture Method, Computer Aided Learning and Problem Based Learning independently and has proved that each method is significant and can prove effective in terms of knowledge retention.

\section{Acknowledgement}

The Author is thankful to administrative authority of NIMS University, Jaipur and Colleges of Nursing from Pune City.

\section{References}

[1] Korean LC, Revolution in technology:Traditional and Modern Teaching Methods.Journal of Nursing Education and Research. 2010 Jul; 27(2): 111-134.

[2] Corean Colins. : Revolution in field of Nursing and its effect on quality patient care.Journal of Nursing Education and Research $8^{\text {th }}$ ed.; 2012. P. 575-586. ISBN: 177866905432.

[3] Lobrean Rebout F.Categories of teaching methods Journal of Nursing Education. 2011 June; 112(2): 666. Doi: $10.142 /$ edu.

[4] Foreigner Lorens T.Ludwings, Borens Porens,Field of education in all the sciences researches are very sparse and similarly in Nursing Education A Journal Of Nursing Research. Journal Articles. 2011 Jan; 7(2):

[5] Cooper,2011, Deren , Selen, Pinues. significant knowledge retention in Nursing students using Problem based learning method Impact of an Education on students. Journal of Research and Education.; 2011(573698): 1-4.

[6] Les PS, Dupin , Teles Marian, Bhupali Preeti, Madhale Milka. Lecture method in terms of knowledge retention 
Journal of Nursing Education and Research. 2012 Jun; 2(1): 99-100.

\section{Author Profile}

Mrs. Vaishali Agre, received M.Sc. Nursing from Bharati Vidyapeeth, Pune, India in 2005 and presently registered as Ph.D. Nursing student in NIMS University, Jaipur, India in 2011.

Dr. Kochu Thresiamma Thomas is Nursing Research Expert, NIMS University, Jaipur

Volume 5 Issue 6, June 2016 www.ijsr.net 